\title{
Characterisation of integrin-linked kinase signalling in sporadic human colon cancer
}

\author{
A Marotta', K Parhar', D Owen², S Dedhar' ${ }^{1,3}$ and B Salh*, \\ 'Jack Bell Research Center, 2660 Oak Street, Vancouver, BC, Canada V6H 3Z6; ²Vancouver General Hospital, 855 WI 2th Ave, Vancouver, BC, Canada \\ V5Z IM9; ${ }^{3}$ BC Cancer Agency, 600 WI Oth Ave, Vancouver, BC, Canada V5Z 4E6
}

\begin{abstract}
The putative oncogene, integrin-linked kinase (ILK) is a protein serine/threonine kinase that has been reported to regulate a number of biological properties including anchorage-independent cell cycle progression, tumour cell invasion and apoptosis. Overexpression of ILK has been documented in a wide variety of human malignancies including Ewing's sarcoma (ES), primitive neural ectodermal tumours (PNETs) and prostate tumours (PT). We recently reported that ILK signalling was also dysregulated in patients with the genetic condition familial adenomatous polyposis (FAP), a precursor to colon cancer. In this study, we extended our previous work by investigating the ILK-signalling pathway in sporadic human colon cancer and representative lymph node metastases. The data indicate that the ILK protein is significantly hyperexpressed in malignant acini in relation to normal crypts. Moreover, overexpression of ILK not only coincided with increased MBP phosphotransferase activity but as well with effects on downstream targets like GSK3 $\beta$. Based upon the presented data, we propose that ILK signalling is dysregulated early during the development of human colon cancer, and that selective inhibition of this molecule alone or in combination with the standard therapeutic modality might be a more effective means of treating colon cancer.

British Journal of Cancer (2003) 88, I755-1762. doi:I0.1038/sj.bjc.6600939 www.bjcancer.com

(c) 2003 Cancer Research UK
\end{abstract}

Keywords: colon cancer; ILK; $\beta$-catenin

Mutation of the adenomatous polyposis coli (APC) gene is an integral event in the genesis of colorectal cancer (Fearon et al, 1990; Kinzler et al, 1991). Mutation of this gene results in the expression of a C-terminally truncated protein that is unable to form a complex with axin, $\beta$-catenin and GSK3 $\beta$ (Behrens et al, 1998; Sparks et al, 1998; Barker et al, 2000; Rowan et al, 2000). Consequently, there is an increase in the cytosolic levels of $\beta$-catenin. Stabilisation of the latter is believed to result in its translocation to the nucleus where it binds to the Tcf-4 (T-cell factor) family of transcription factors resulting in the expression of a number of different genes that have been implicated in oncogenesis. These include cyclin D1, c-myc and the matrix metalloproteinase (MMP)-7 (He et al, 1998; Crawford et al, 1999; Shtutman et al, 1999). However, whether mutation of APC alone is sufficient in dysregulating $\beta$-catenin signalling or whether additional signals are required for this disruption are currently unclear. In this regard, a prominent nuclear $\beta$-catenin signal was documented in cells that overexpress the integrin-linked kinase (ILK), duplicating the events associated with the mutation of APC. Translocation of $\beta$-catenin accompanied the activation of Tcf-4dependent gene transcription (Novak et al, 1998).

The ILK, which was discovered through its interactions with the $\beta 1$ integrin subunit (Hannigan et al, 1996), has been demonstrated

* Correspondence: Dr B Salh, Department of Medicine, Jack Bell Research Center, 2660 Oak Street, Vancouver, BC, Canada V6H 3Z6; E-mail: bsalh@interchange.ubc.ca

Received 31 October 2002; revised 21 January 2003; accepted 10 February 2003 to mediate a plethora of biological events. This putative oncogene has not only been described as an immunohistochemical marker for the identification of Ewing's sarcoma (ES) and primitive neuroectodermal tumours (PNET), but as well increased expression of the protein has been demonstrated to be inversely related to the 5-year survival rate in prostate cancer (Chung et al, 1998; Graff et al, 2001). In addition to this, we demonstrated that ILK signalling is dysregulated in patients diagnosed with familial adenomatous polyposis (FAP) (Marotta et al, 2001). In the present study, we sought to determine the extent to which this pathway was disrupted in sporadic cases of colon cancer. The results from these studies demonstrate that ILK is hyperexpressed in malignant crypts from both the primary and metastatic lesions. In addition to this, we demonstrate that there was approximately a 2-9-fold increase in ILK immunoprecipitated MBP phosphotransferase activity in relation to normal colonic crypts. Furthermore, we report that changes in ILK activity coincide with changes on downstream targets, primarily GSK $3 \beta$. Based upon our findings, we conclude that dysregulation of the ILK-signalling nexus is an important early event in the genesis of human colon cancer.

\section{MATERIALS AND METHODS}

\section{Materials}

Rabbit polyclonal antibodies for ILK (IB/IHC), PKB and GSK3 $\beta$ were kindly provided by Stressgen Biotechnologies Inc. (Victoria, BC, Canada). Monoclonal anti-ILK (IP) and MBP were obtained from Upstate Biotechnology Inc. (Lake Placid, NY, USA). 
Anti-phosphospecific-PKB Ser473 and GSK3 $\beta$ Ser-9 were obtained from New England Biolabs Inc. (Beverly, MA, USA). Horse-radish peroxidase-conjugated secondary antibodies were obtained through Calbiochem (San Diego, CA, USA). cAMP-dependent protein kinase inhibitor peptide, EGTA, EDTA, MOPS, PMSF, sodium orthovanadate, leupeptin, aprotinin, benzamidine, dithiothreitol and $\beta$-glycerolphosphate were purchased from Sigma, Sigma-Aldrich, Oakville, Ontario.

\section{Tissue procurement}

We obtained a total of 38 cases of human colon cancer through Dr D Owen from the Division of Anatomical Pathology at Vancouver Hospital and Health Sciences Centre (VH\&HSC). The 38-paired cases were used for biochemical analysis. In all, 16 of the cases, which were utilised in these studies, were selected for immunohistochemical analysis on the basis that lymph node metastases were present. Ethical consent for these studies was obtained from each of the patients and by boards governing research at the University of British Columbia and VH\&HSC.

\section{Preparation of human tissue samples}

The tissue samples were serially sectioned $(3-5 \mu \mathrm{m}$ in diameter) using a cryostat, and approximately 20 slices were placed in $1 \mathrm{ml}$ of homogenisation buffer containing $20 \mathrm{~mm}$ MOPS, $50 \mathrm{~mm} \beta$-glycerolphosphate, $50 \mathrm{~mm}$ sodium fluoride, $1 \mathrm{~mm}$ sodium vanadate, $5 \mathrm{~mm}$ EGTA, $2 \mathrm{~mm}$ EDTA, 1\% NP40, $1 \mathrm{~mm}$ dithiothreitol, $1 \mathrm{~mm}$ benzamidine, $1 \mathrm{~mm}$ phenylmethanesulphonylfluoride and $10 \mu \mathrm{g} \mathrm{ml}^{-1}$ leupeptin as previously described (Marotta et al, 2001).

\section{Sodium dodecylsulphate-polyacrylamide gel electrophoresis (SDS-PAGE)}

Protein samples for immunoblotting were resolved using SDSPAGE. Proteins were transferred onto the nitrocellulose membrane in a BioRad transfer apparatus and the nitrocellulose membrane was blotted with the appropriate antibody at a dilution of $1: 1000$ in $0.05 \%$ Tween-TBS. The resulting membrane was exposed to ECL for $1 \mathrm{~min}$, and then to film to visualize the immunoreactive proteins.

\section{Immunoprecipitation}

A total of $400 \mu \mathrm{g}$ of the appropriate sample was subjected to a preclear step with a nonspecific rabbit Ig $\mathrm{G}$ antibody preabsorbed to protein A Sepharose for a minimum of $1 \mathrm{~h}$ at $4{ }^{\circ} \mathrm{C}$. The samples were then centrifuged at 6000 r.p.m. and equal volumes of the supernatent were taken and aliquoted into a new microfuge tube. The lysate was then incubated with $4 \mu \mathrm{g}$ of the appropriate antibody overnight at $4{ }^{\circ} \mathrm{C}$ with gentle mixing. To each vial, $30 \mu \mathrm{l}$ protein A Sepharose was added for an additional $1 \mathrm{~h}$ at $4^{\circ} \mathrm{C}$. The lysates were then centrifuged and the supernatent was discarded. The protein A Sepharose beads conjugated to the antibody were washed twice with the standard lysis buffer and twice with protein kinase reaction buffer (100 mM Hepes pH 7.0, $2 \mathrm{mM} \mathrm{MgCl}_{2}, 2 \mathrm{~mm}$ $\mathrm{MnCl}_{2}$ and $2 \mathrm{~mm} \mathrm{Na}$ orthovanadate).

\section{Immune complex kinase assays}

The beads were pelleted and the reaction was started by the addition of $25 \mu \mathrm{l}$ of the kinase reaction buffer ( $50 \mathrm{~mm}$ Hepes $\mathrm{pH}$ 7.0, $1 \mathrm{mM} \mathrm{MgCl}_{2}, 1 \mathrm{mM} \mathrm{MnCl}_{2}$, and $1 \mathrm{~mm} \mathrm{Na}$ orthovanadate), $2 \mathrm{~mm}$ $\mathrm{NaF}, 5 \mu \mathrm{g}$ of MBP per tube and $0.5 \mu \mathrm{g}$ of ATP $(250 \mu \mathrm{M}$ ATP, $\left.1 \mu \mathrm{Ci}\left[\gamma^{32} \mathrm{P}\right] \mathrm{ATP}\right)$ at $30^{\circ} \mathrm{C}$ for $20 \mathrm{~min}$. The reaction was terminated with the addition of $10 \mu \mathrm{l}$ of $4 \times$ sample buffer. The tubes were microfuged at maximum for $1 \mathrm{~min}$ and the proteins were resolved on a $14 \%$ SDS-PAGE gel. The resulting gel was stained with
Coomassie Blue as outlined above and phosphorylation of the substrate was visualised by autoradiography.

\section{Immunohistochemistry}

Formalin-fixed paraffin-embedded tissue sections were obtained through the Division of Anatomical Pathology at VH\&HSC. Immunohistochemical staining for ILK $(1: 100)$ and phosphoSer473 PKB (1:100) was carried out using a standard streptavidin-biotin technique. Antigen retrieval was performed by pressure-cooking the sections in a $0.01 \mathrm{M}$ citrate buffer for $10 \mathrm{~min}$ at high power using a $925-\mathrm{W}$ microwave oven. The slides were then incubated with the appropriate primary antibody at a pre-determined concentration overnight at room temperature. Following incubation, the sections were rinsed three consecutive times with PBS and then incubated with the appropriate biotinylated secondary antibody for $1 \mathrm{~h}$ followed by incubation with peroxidase-labelled streptavidin. AEC substrate was used as the chromagen and the sections were counterstained with haematoxylin. Three observers independently examined all the stained immunoreactive positivity was assessed by uniform red staining.

The staining intensity (weak $=1$, intermediate $=2$ and strong $=3$ ) was scored by three independent examiners (AM, DO and $\mathrm{BS})$, and the results are expressed as the mean \pm s.d.

\section{Statistical analysis}

The relative amounts of protein were measured by scanning the film using the BioRad gel-doc apparatus into a TIFF format file. The numerical densitometric values were assigned arbitary values on a scale of 1-3 for immunohistochemistry. The band densities and the results are expressed as mean \pm s.d., with $P<0.05$ being considered significant using the Student's $t$-test (unpaired, two-tailed).

\section{RESULTS}

\section{ILK expression is dysregulated in sporadic cases of colon cancer}

A recent report from our laboratory indicated that the expression and activity of ILK is perturbed in polypoid lesions resected from patients diagnosed with the autosomal dominant condition, FAP (Marotta et al, 2001). To determine whether ILK was also dysregulated in sporadic cases of human colon cancer, we examined both the protein expression of ILK by immunohistochemical analysis and the mRNA levels using microarray technology.

Immunohistochemical analysis revealed that the protein levels of ILK were dramatically increased in the cancerous acini when compared to the normal adjacent control crypts based on the intensity of the chromagen (Figure 1A; upper panel). This increase in the protein expression of ILK was further apparent at higher magnification (Figure 1A, lower panels). The results are corroborated by the micrographs presented in Figure 1B-G, which represent three separate cases. These results clearly demonstrate that the protein expression of ILK is increased in the cancerous crypts (panels $\mathrm{C}, \mathrm{E}, \mathrm{G}$ ) with respect to the adjacent control tissue for each case (panels B, D, F).

To determine whether overexpression of ILK within these lesions was statistically significant, the relative staining intensity for each case was scored. The data thus obtained revealed that the increase in ILK in the cancerous crypts was highly significant $(P<0.0005)$. There was approximately a three-fold increase in the expression of ILK in the cancerous acini (2.22) when compared to the normal adjacent tissue $(0.75$, Figure 3$)$. It is worth noting that although ILK immunoreactivity was observed in the stromal component of both the normal and cancerous lesions, this staining was not taken into account when quantifying the intensity of the 
A



B

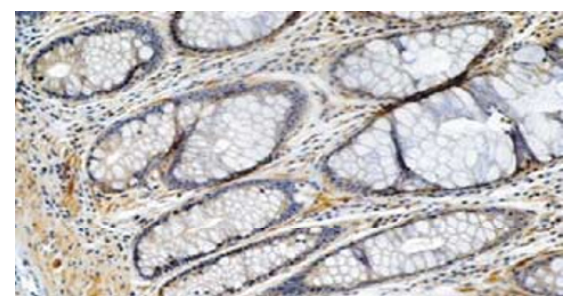

D

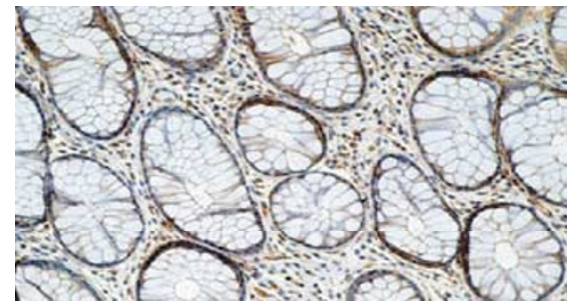

F

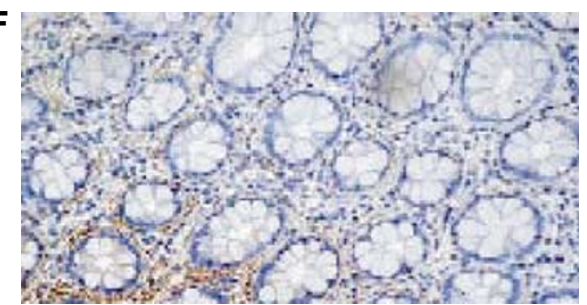

C

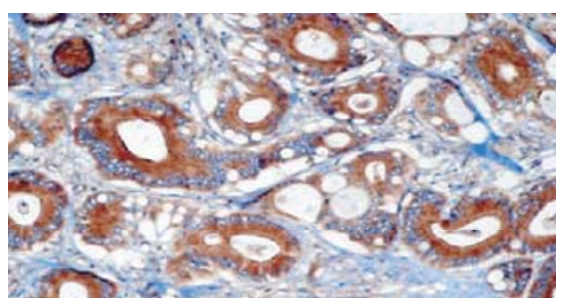

E
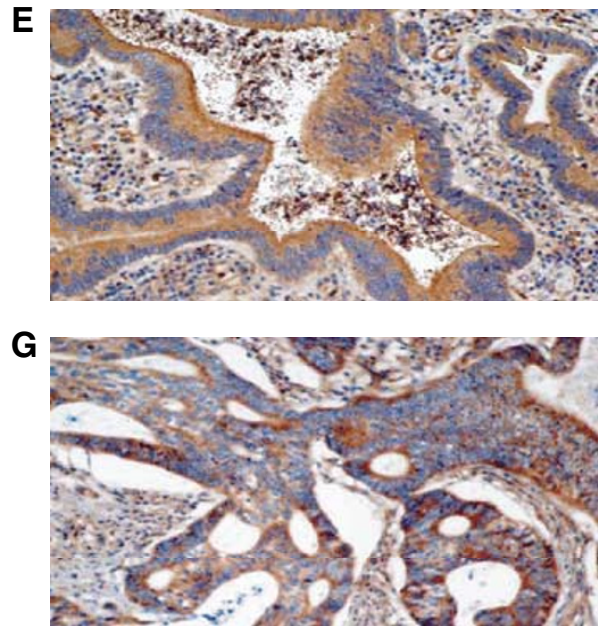

Figure I Over-expression of ILK in sporadic colorectal cancers. Panel A: representative case examining ILK expression in the control crypts vs cancerous crypts at a lower magnification $(\times 100)$ as well as at a higher magnification $(\times 200)$. Panels $\mathbf{B}-\mathbf{G}$ : three additional representative cases demonstrating enhanced ILK expression in the cancerous lesions $(\mathbf{C}, \mathbf{E}, \mathbf{G})$ when compared with the normal control $(\mathbf{B}, \mathbf{D}, \mathbf{F})$. Staining was performed as outlined in the Materials and Methods section.

chromagen for statistical analysis. ILK immunoreactivity within the stromal component of tissue is not an unexpected finding, since this protein is ubiquitously expressed (Li et al, 1999). Analysis of the mRNA levels indicated that there was no significant differences in the ILK mRNA levels between any of the controls and primary lesions analysed (data not shown). Thus, it appears that the increased ILK protein expression likely reflects a change in protein stabilisation as opposed to a change in the level of the message.

\section{ILK expression in regional lymph nodes}

A number of studies have underscored the importance of ILK in mediating cell migration and invasion. In this regard, over- expression of ILK has been reported to upregulate the levels of MMP-9 in an AP-1-dependent manner. Moreover, treatment with the selective ILK inhibitor (termed KP-SD1) was shown to inhibit MMP-9 promoter activity as well as lead to a reduction in the invasive potential of intestinal and mammary epithelial cells (Troussard et al, 2000).

To characterise the protein expression of ILK in metastatic lesions, 16 cases were selected on the basis that metastatic deposits were present in the regional lymph nodes. The representative results from these studies are presented in Figure 2. In Figure 2A, which represents a control lymph node, a moderate chromagenic signal is present in a small proportion of the lymphocytes as well as the lymphatic vessels (yellow arrow head). In Figure 2B-E, which represents four individual cases with positive lymph nodes, 
A

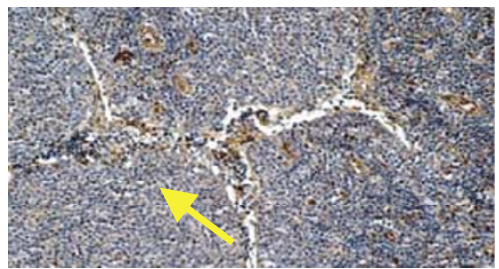

B

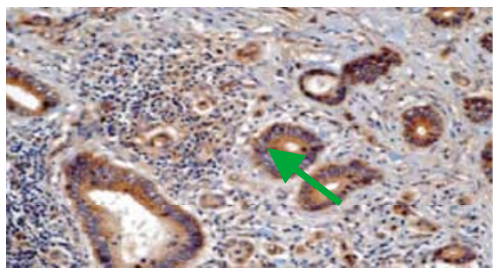

C

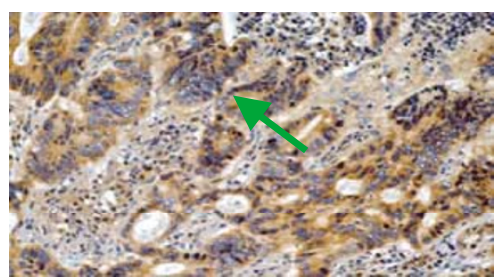

D

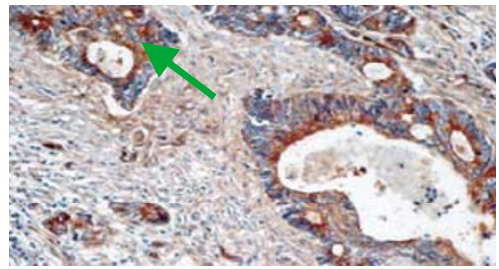

E

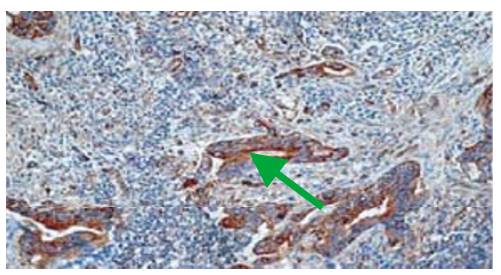

Figure 2 ILK expression in positive lymph nodes. Panel $\mathbf{A}$, expression of ILK in a lymph node negative for tumour cell infiltration. Panels $\mathbf{B}-\mathbf{E}$, expression of ILK in four tumour cell positive lymph nodes. Immunohistochemical analysis of ILK was performed as outlined in the Materials and Methods section.

a strong chromagenic signal is observed predominantly in the malignant acini (green arrow heads). To delineate the extent to which the protein expression of ILK was altered during the metastatic process, the relative staining intensity was quantified and compared to the control tissue as well as the primary cancer. The results presented in Figure 3 indicate that the protein expression of ILK is significantly increased approximately fourfold in the malignant acini of the regional lymph nodes when compared to the normal colonic crypts $(P<0.00001)$. There was no significant difference in the expression of ILK between the primary cancer and the metastatic deposit within regional lymph nodes $(P=0.1)$. Based upon these results, it appears that changes in the expression of ILK occur prior to changes in the metastatic potential of colon cancer cells.

\section{ILK activity is increased in colonic cancers}

In our previous study, we demonstrated that overexpression of ILK in colonic polyps coincided with an increase in the

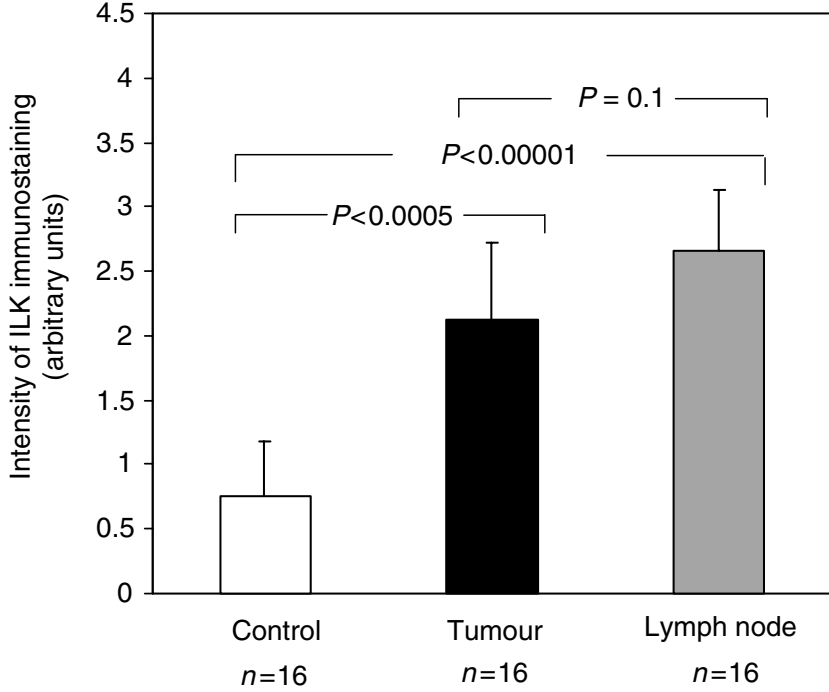

Figure 3 ILK expression is significantly increased in colorectal cancers. Mean expression of ILK in 16 cases of colon cancer with positive lymph nodes. The intensity of the chromagen (weak $=1$, moderate $=2$, strong $=3$ ) was scored as outlined in the Materials and Methods section by three independent examiners. The results for the 16 cases are expressed as the mean \pm s.d.

immunoprecipitated ILK MBP phosphotransferase activity (Marotta et al, 2001). To determine whether ILK activity was similarly affected in human colon cancer, we characterised the biochemical activity in a total of 38 cases (16 cases in which metastatic deposits were present in the regional lymph nodes; an additional 22 cases with no lymphatic invasion). The representative data (Figure 4A) indicate that changes in the expression of ILK (lower panel) coincided with changes in the MBP phosphotransferase activity in the cancerous lesions when compared to the normal adjacent control tissue. Two- to nine-fold increases in ILK activity were evident in 24 out of the 38 cases (63\%). To determine whether there was a direct correlation between ILK expression and activity levels, the percentage change in the ILK activity above the control was compared with the percentage change in the ILK expression above the control (see Figure 4C). Although both displayed increased levels, a direct correlation was not apparent between them. It is worth adding that there were no measurable differences in the ILK protein expression between primary tumours with or without positive lymph nodes. Importantly, changes in the expression and activity of ILK appeared to be independent of changes in the protein expression of Erk1 and Erk2 in the same lesions. These results are in keeping with a number of reports that have examined the relative expression and activity of Erk1 and Erk2 in human malignancies such as colonic and pancreatic cancer (Attar et al, 1996; Yip-Schneider et al, 1999).

Since ILK has been shown to regulate GSK3 $\beta$ activity (Delcommenne et al, 1998) as well as modulate the subcellular distribution of $\beta$-catenin (Novak et al, 1998), we wanted to determine whether changes in ILK activity correlated with effects on these downstream targets in vivo. For the representative patient (Figure 4B), changes in the MBP phosphotransferase activity appeared to coincide with not only the overexpression of the ILK protein but as well with the stabilisation of $\beta$-catenin. Changes in the expression of the latter are not surprising, since approximately $85 \%$ of all sporadic colorectal cancers are believed to arise because of mutations in the APC gene (Mei et al, 1999). Interestingly, we observed an impressive increase in the phosphorylation of GSK3 $\beta$ at Ser-9 by immunoblotting with a phosphospecific GSK3 $\beta$ Ser-9 antibody as well as by retardation in the electrophoretic mobility 
of the GSK3 $\beta$ protein itself. Phosphorylation of GSK3 $\beta$ at Ser-9 coincides with a decrease in its phosphotransferase activity. These findings consolidate our preliminary data in colonic polyposis (Marotta et al, 2001) and indicate that this dysregulation is a stable reproducible event in multistage colon carcinogenesis. Addition-


B

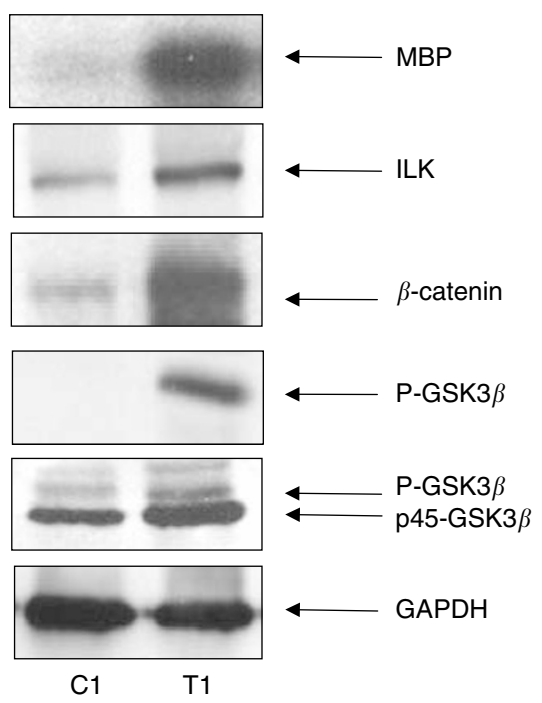

C



ally, elevated expression and activity of ILK appeared to be associated with an increase in the protein expression of Lef-1 (data not shown), a downstream target of ILK (Novak et al, 1998). The expression of GAPDH was assessed to control for protein loading.

There are a number of reports, which indicate that Ser473 of PKB is phosphorylated by an array of protein kinases including Mapkapk-2, PDK1/PRK2 and PKC. ILK has also been described as the putative PDK2 that phosphorylates this site on PKB. In this regard, ILK has been demonstrated to phosphorylate Ser473 in vitro and in vivo. Furthermore, modulation of ILK activity with a specific inhibitor (KP-SD1) has been reported to coincide with a decrease in Ser473 phosphorylation as well as modulate the activity of the respective kinase. Transient and stable overexpression of the ILK protein is known to correlate with an increase in not only Ser473 phosphorylation but also the biochemical activity of PKB.

To determine if changes in ILK expression resulted in changes in the phosphorylation status of PKB, we examined Ser473 phosphorylation by immunohistochemical analysis in the 16 cases in which metastatic lesions were present. The results, which are presented in Table 1, indicate that changes in PKB Ser473 phosphorylation occur infrequently in this disease based upon the intensity of the chromagen. These results are further corroborated by evidence indicating that there were no significant

Table I Relative PKB Ser473 phosphorylation staining intensity

\begin{tabular}{|c|c|c|c|}
\hline Case number & Control & Primary cancer & Metastatic lesion \\
\hline 3 & 1 & 1 & 1 \\
\hline 4 & 1 & 1 & 1 \\
\hline 6 & i & 2 & 2 \\
\hline 8 & 1 & 1 & 1 \\
\hline 9 & i & i & i \\
\hline 12 & । & I & 1 \\
\hline 15 & 1 & I & 1 \\
\hline 22 & 1 & 1 & | \\
\hline 23 & 1 & 1 & 1 \\
\hline 25 & i & i & i \\
\hline 26 & 1 & 1 & 2 \\
\hline 27 & 1 & 2 & 2 \\
\hline 32 & 1 & | & | \\
\hline 33 & 1 & i & i \\
\hline 35 & i & i & i \\
\hline 38 & 1 & 1 & 1 \\
\hline
\end{tabular}

Tissue sections corresponding to either control, primary cancer or metastatic lesion were stained as outlined in the Materials and Methods section.

Figure 4 ILK signalling is dysregulated in human colon cancer. (A) ILK activity is enhanced in colorectal cancers. Upper panel, ILK MBP phosphotransferase densitometry. Immunoprecipitated ILK MBP phosphotransferase performed in triplicate. Middle panel, anti-ILK immunoblot, examining the protein expression of ILK in the tumour and the corresponding control sample. Lower panel; anti-Erkl-CT immunoblot, examining the expression of Erkl and Erk2 in the control samples vs the corresponding tumour. (B) Effects of ILK on downstream targets. ILK activity is increased in the polyp compared with its respective control (representative autoradiogram). Anti-ILK immunoblot, examining expression of ILK. Anti- $\beta$-catenin immunoblot, examining the expression of $\beta$ catenin. Anti-P-GSK3 $\beta$ immunoblot, examining phosphorylation status of GSK3 $\beta$. Anti-GSK3 $\beta$ immunoblot, examining expression of GSK3 $\beta$. AntiGAPDH immunblot, used as an internal control for experiments. The results are representative for the 24 cases, which displayed increases in ILK activity. (C) Correlation between the expression and activity of ILK in colonic tumours. The band intensities were quantitated as outlined in the Materials and Methods section. The values are represented as a percentage change in activity/expression above the corresponding control sample. 
differences in immunoprecipitated PKB HH2B phosphotransferase activity between the control and tumour samples analysed (data not shown). These findings in colon cancer are supported by our recent findings in human breast cancer, which demonstrated that there were no statistically significant differences in PKB activity between the control and tumour samples analysed (Salh et al, 2002). To add further support, mammary tumours induced by specific overexpression of ILK correlated with a dramatic increase in the Ser-9 phosphorylation of GSK3 $\beta$. However, only modest differences in the Ser473 phosphorylation status of $\mathrm{PKB}$ were observed in this animal model (White et al, 2001). Thus, it appears that ILK is more likely to regulate GSK3 $\beta$ activity directly in vivo, and dysregulation of this nexus, rather than $\mathrm{PKB}$, might have an important role in epithelial-derived tumour growth and survival. It is also possible, however, that only modest changes in PKB activity are required for the antiapoptotic effect this kinase provides.

\section{DISCUSSION}

In the present study, we report for the first time that the expression of ILK is significantly increased in sporadic colon cancer and metastatic deposits in regional lymph nodes, thus substantiating our original findings in colonic polyposis. We also show that increased immunoprecipitated ILK MBP phosphotransferase activity was evident in $63 \%$ of the cases. In addition to this, we demonstrate that elevated ILK expression and increased MBP phosphotransferase activity coincide with effects on downstream targets of ILK signalling such as GSK $3 \beta$ phosphorylation. Based upon the data presented here and in keeping with the 'just right' model for colorectal carcinogenesis, which states that specific APC genotypes are selected during tumour formation on the basis of the specific level of residual $\beta$-catenin downregulating activity that is retained, additional signals are likely required for the development of human colon cancer (Albuquerque et al, 2002). Perhaps ILK, via its effects on Wnt signalling, acts in concert with the loss of APC function to facilitate disease progression. It is worth adding that a fine balance must exist between those signals that influence Wnt signalling in a positive $v s$ a negative manner since excessive accumulation of $\beta$-catenin has been reported to coincide with the induction of apoptosis (Kim et al, 2000).

One of the important observations made in these studies was the identification that GSK $3 \beta$ is phosphorylated at Ser-9, which is indicative of its inhibition. This could be of primary importance as it suggests that (pre)malignant cells retain the ability to modulate signalling pathways which ultimately regulate the subcellular distribution of $\beta$-catenin and that this regulation is probably a consequence of the 'second hit' in the wild-type APC allele (Albuquerque et al, 2002). This is in agreement with the 'just right' model. It is possible that ILK-mediated inhibition of GSK $3 \beta$ could destabilise the formation of the 'destruction complex' since phosphorylation of axin and APC by GSK $3 \beta$ is said to favour the formation of the complex (reviewed in Fodde et al, 2001). In addition to this, inhibition of GSK3 $\beta$ by ILK could tip the scale in favour of enhanced growth. Overexpression of ILK has been shown to promote anchorage-independent cell cycle progression, which is likely mediated by the upregulation of Tcf4-dependent gene transcription as well as by the inhibition of GSK3 $\beta$. Interestingly, GSK $3 \beta$ is known to phosphorylate cyclin D1; phosphorylation is essential for degradation of the latter by the ubiquitinproteasomal complex (Diehl et al, 1998). It is well established that the levels of cyclin D1 are increased in this disease (Kristt et al, 2000; Utsunomiya et al, 2001). In addition to the putative effects of GSK3 $\beta$ on growth, inhibition of this kinase could favour cell survival. A number of studies have shown that GSK3 $\beta$ can modulate apoptosis (Frame and Cohen, 2001; King et al, 2001).
As outlined above, $63 \%$ of the cases in which the biochemical activity of ILK was assessed displayed changes in the MBP phosphotransferase activity, whereas all of the lesions evaluated using immunohistochemistry demonstrated significant changes in ILK expression. This discrepancy between the expression and activity of ILK could be attributable to various factors involved in tissue sampling, such as the extent of tumour vascularisation and time of harvesting (normally less than $2 \mathrm{~h}$ ) or even quite possibly because of differences in the proposed etiological pathways, that is, MIN vs CIN. However, in conjunction with our previous findings in FAP, it is plausible to assume that overexpression of and increased activity of ILK could be an important event not only in the initiation of colorectal carcinogenesis but as well in the progression of the disease. Support for the role of ILK in carcinogenesis is provided by elegant recent work, which investigated mammary epithelial-specific expression of ILK. The results from these studies indicated that overexpression of ILK not only resulted in the formation of multiple hyperplastic foci but as well a number of the transgenic mice developed focal mammary tumours (White et al, 2001).

Since ILK has been reported to enhance tumour cell invasion (Troussard et al, 2000), we postulated that ILK expression might be further dysregulated during the metastatic process. Surprisingly, the data from these studies indicated that there were no significant differences in the expression of ILK between the primary tumours and the metastatic deposits located within the regional lymph nodes. These data, in conjunction with our previous findings in colorectal adenomas from patients with FAP, suggest that changes in the expression of ILK occur very early during the development of colon cancer. It is plausible to assume, however, that although there were no significant differences in the expression of ILK between the primary and metastatic deposits, perhaps the activity of ILK is dysregulated at the invasive front. In support of this and in conjunction with the known effects of ILK on Tcf-dependent gene transcription, dramatic shifts in the subcellular distribution of $\beta$-catenin were shown to occur at the leading edge of the tumour (Kirchner and Brabletz, 2000; Jung et al, 2001). Furthermore, the tumour invasive front exhibits an epithelialmesenchymal transition, as well as a loss of E-cadherin expression (Brabletz et al, 2001). Notably in this regard, over-expression of ILK has been reported to result in the downregulation of Ecadherin (Novak and Dedhar, 1999), whereas administration of a selective inhibitor of ILK has been reported to result in the induction of E-cadherin expression (Tan et al, 2001). Certainly, ILK has been reported to promote epithelial to mesenchymal transition in mammary epithelium (Somasiri et al, 2001). In order to specifically address the role of ILK activity at the invasive front, the development of specific antibodies capable of detecting the activated form of ILK would be required. We were unable to demonstrate any significant changes using an antibody specific for the activated form of PKB.

In summary, we suggest that dysregulation of ILK signalling is an important early event in the genesis of human colon cancer. Furthermore, with the recent surge in the development of specific inhibitors to protein kinases, we propose that an inhibitor to ILK should be explored as a possible novel strategy for either the treatment and/or prevention of this disease. An inhibitor to this protein kinase could prove to be as efficacious as the tyrosine kinase inhibitor STI-571, which is used in the treatment of chronic myeloid leukaemia (Thiesing et al, 2000; Joensuu et al, 2001). Moreover, administration of an ILK inhibitor in combination with other chemotherapeutic drugs might prove to be as useful as the EKI-569 (a reversible inhibitor of the EGF receptor tyrosine kinase) sulindac combination (Torrance et al, 2000). Currently, we are evaluating whether changes in ILK expression/ activity occur predominantly in CIN vs MIN lesions. As well, we are attempting to unravel the mechanism by which ILK is 
dysregulated in colon cancer. Undoubtedly, this information could provide further insight into the underlying mechanisms involved in the initiation of carcinogenesis within the colon, as well as enhance our understanding of the 'just right' model for carcinogenesis.

\section{REFERENCES}

Albuquerque C, Breukel C, van der Luijt R, Fidalgo P, Lage P, Slors FJ, Leitao CN, Fodde R, Smits R (2002) The 'just-right' signaling model: APC somatic mutations are selected based on a specific level of activation of the beta-catenin signaling cascade. Hum Mol Genet 11: 1549-1560

Attar BM, Atten MJ, Holian O (1996) MAPK activity is down-regulated in human colon adenocarcinoma: correlation with PKC activity. Anticancer Res 16: 395 - 399

Barker N, Morin PJ, Clevers H (2000) The Yin-Yang of TCF/beta-catenin signaling. Adv Cancer Res 77: 1-24

Behrens J, Jerchow BA, Wurtele M, Grimm J, Asbrand C, Wirtz R, Kuhl M, Wedlich D, Birchmeier W (1998) Functional interaction of an axin homolog, conductin, with beta-catenin, APC, and GSK3beta. Science 280: $596-599$

Brabletz T, Jung A, Reu S, Porzner M, Hlubek F, Kunz-Schughart LA, Knuechel R, Kirchner T (2001) Variable beta-catenin expression in colorectal cancers indicates tumor progression driven by the tumor environment. Proc Natl Acad Sci USA 98: 10356-10361

Chung DH, Lee JI, Kook MC, Kim JR, Kim SH, Choi EY, Park SH, Song HG (1998) ILK (beta1-integrin-linked protein kinase): a novel immunohistochemical marker for Ewing's sarcoma and primitive neuroectodermal tumour. Virchows Arch 433: 113-117

Crawford HC, Fingleton BM, Rudolph-Owen LA, Goss KJ, Rubinfeld B, Polakis P, Matrisian LM (1999) The metalloproteinase matrilysin is a target of beta-catenin transactivation in intestinal tumors. Oncogene 18: $2883-2891$

Delcommenne M, Tan C, Gray V, Rue L, Woodgett J, Dedhar S (1998) Phosphoinositide-3-OH kinase-dependent regulation of glycogen synthase kinase 3 and protein kinase B/AKT by the integrin-linked kinase. Proc Natl Acad Sci USA 95: 11211-11216

Diehl JA, Cheng M, Roussel MF, Sherr CJ (1998) Glycogen synthase kinase3beta regulates cyclin D1 proteolysis and subcellular localization. Genes Dev 12: $3499-3511$

Fearon ER, Cho KR, Nigro JM, Kern SE, Simons JW, Ruppert JM, Hamilton SR, Preisinger AC, Thomas G, Kinzler KW, Vogelstein B (1990) Identification of a chromosome $18 \mathrm{q}$ gene that is altered in colorectal cancers. Science 247: 49-56

Fodde R, Smits R, Clevers H (2001) APC signal transduction and genetic instability in colorectal cancer. Nat Rev Cancer 1: 55-67

Frame S, Cohen P (2001) GSK3 takes centre stage more than 20 years after its discovery. Biochem J 359: 1-16

Graff JR, Deddens JA, Konicek BW, Colligan BM, Hurst BM, Carter HW, Carter JH (2001) Integrin-linked kinase expression increases with prostate tumor grade. Clin Cancer Res 7: 1987-1991

Hannigan GE, Leung-Hagesteijn C, Fitz-Gibbon L, Coppolino MG, Radeva G, Filmus J, Bell JC, Dedhar S (1996) Regulation of cell adhesion and anchorage-dependent growth by a new beta 1-integrin-linked protein kinase. Nature 379: 91 - 96

He TC, Sparks AB, Rago C, Hermeking H, Zawel L, da Costa LT, Morin PJ, Vogelstein B, Kinzler KW (1998) Identification of c-MYC as a target of the APC pathway. Science 281: $1509-1512$

Joensuu H, Roberts PJ, Sarlomo-Rikala M, Andersson LC, Tervahartiala P, Tuveson D, Silberman S, Capdeville R, Dimitrijevic S, Druker B, Demetri GD (2001) Effect of the tyrosine kinase inhibitor STI571 in a patient with a metastatic gastrointestinal stromal tumor. $N$ Engl $J$ Med 344: $1052-1056$

Jung A, Schrauder M, Oswald U, Knoll C, Sellberg P, Palmqvist R, Niedobitek G, Brabletz T, Kirchner T (2001) The invasion front of human colorectal adenocarcinomas shows co-localization of nuclear betacatenin, cyclin D1, and p16INK4A and is a region of low proliferation. Am J Pathol 159: 1613-1617

Kim K, Pang KM, Evans M, Hay ED (2000) Overexpression of beta-catenin induces apoptosis independent of its transactivation function with LEF-1 or the involvement of major G1 cell cycle regulators. Mol Biol Cell 11: $3509-3523$

\section{ACKNOWLEDGEMENTS}

This work was supported in part by grants from the Cancer Research Society and the Canadian Society for Intestinal Research to BS, and from the National Cancer Institute of Canada to SD.

King TD, Bijur GN, Jope RS (2001) Caspase-3 activation induced by inhibition of mitochondrial complex I is facilitated by glycogen synthase kinase-3beta and attenuated by lithium. Brain Res 919: 106-114

Kinzler KW, Nilbert MC, Su LK, Vogelstein B, Bryan TM, Levy DB, Smith KJ, Preisinger AC, Hedge P, McKechnie D, et al (1991) Identification of FAP locus genes from chromosome 5q21. Science 253: $661-665$

Kirchner T, Brabletz T (2000) Patterning and nuclear beta-catenin expression in the colonic adenoma-carcinoma sequence. Analogies with embryonic gastrulation. Am J Pathol 157: 1113-1121

Kristt D, Turner I, Koren R, Ramadan E, Gal R (2000) Overexpression of cyclin D1 mRNA in colorectal carcinomas and relationship to clinicopathological features: an in situ hybridization analysis. Pathol Oncol Res 6: 65-70

Li F, Zhang Y, Wu C (1999) Integrin-linked kinase is localized to cellmatrix focal adhesions but not cell-cell adhesion sites and the focal adhesion localization of integrin-linked kinase is regulated by the PINCH-binding ANK repeats. J Cell Sci 112: 4589-4599

Marotta A, Tan C, Gray V, Malik S, Gallinger S, Sanghera J, Dupuis B, Owen D, Dedhar S, Salh B (2001) Dysregulation of integrin-linked kinase (ILK) signaling in colonic polyposis. Oncogene 20: 6250-6257

Mei JM, Hord NG, Winterstein DF, Donald SP, Phang JM (1999) Differential expression of prostaglandin endoperoxide $\mathrm{H}$ synthase-2 and formation of activated beta-catenin-LEF-1 transcription complex in mouse colonic epithelial cells contrasting in Apc. Carcinogenesis 20: $737-740$

Novak A, Dedhar S (1999) Signaling through beta-catenin and Lef/Tcf. Cell Mol Life Sci 56: $523-537$

Novak A, Hsu SC, Leung-Hagesteijn C, Radeva G, Papkoff J, Montesano R, Roskelley C, Grosschedl R, Dedhar S (1998) Cell adhesion and the integrin-linked kinase regulate the LEF-1 and beta-catenin signaling pathways. Proc Natl Acad Sci USA 95: 4374-4379

Rowan AJ, Lamlum H, Ilyas M, Wheeler J, Straub J, Papadopoulou A, Bicknell D, Bodmer WF, Tomlinson IP (2000) APC mutations in sporadic colorectal tumors: a mutational 'hotspot' and interdependence of the 'two hits'. Proc Natl Acad Sci USA 97: 3352-3357

Salh B, Marotta A, Wagey R, Sayed M, Pelech S (2002) Dysregulation of phosphatidylinositol 3-kinase and downstream effectors in human breast cancer. Int J Cancer 98: 148 - 154

Shtutman M, Zhurinsky J, Simcha I, Albanese C, D'Amico M, Pestell R, Ben-Ze'ev A (1999) The cyclin D1 gene is a target of the beta-catenin/ LEF-1 pathway. Proc Natl Acad Sci USA 96: 5522-5527

Somasiri A, Howarth A, Goswami D, Dedhar S, Roskelley CD (2001) Overexpression of the integrin-linked kinase mesenchymally transforms mammary epithelial cells. J Cell Sci 114: 1125-1136

Sparks AB, Morin PJ, Vogelstein B, Kinzler KW (1998) Mutational analysis of the APC/beta-catenin/Tcf pathway in colorectal cancer. Cancer Res 58: $1130-1134$

Tan C, Costello P, Sanghera J, Dominguez D, Baulida J, de Herreros AG, Dedhar S (2001) Inhibition of integrin linked kinase (ILK) suppresses beta-catenin-Lef/Tcf-dependent transcription and expression of the Ecadherin repressor, snail, in APC-/- human colon carcinoma cells. Oncogene 20: 133 - 140

Thiesing JT, Ohno-Jones S, Kolibaba KS, Druker BJ (2000) Efficacy of STI571, an abl tyrosine kinase inhibitor, in conjunction with other antileukemic agents against bcr-abl-positive cells. Blood 96: $3195-3199$

Torrance CJ, Jackson PE, Montgomery E, Kinzler KW, Vogelstein B, Wissner A, Nunes M, Frost P, Discafani CM (2000) Combinatorial chemoprevention of intestinal neoplasia. Nat Med 6: 1024-1028

Troussard AA, Costello P, Yoganathan TN, Kumagai S, Roskelley CD, Dedhar S (2000) The integrin linked kinase (ILK) induces an invasive phenotype via AP-1 transcription factor-dependent upregulation of matrix metalloproteinase 9 (MMP-9). Oncogene 19: $5444-5452$ 
Utsunomiya T, Doki Y, Takemoto H, Shiozaki H, Yano M, Sekimoto M, Tamura S, Yasuda T, Fujiwara Y, Monden M (2001) Correlation of betacatenin and cyclin D1 expression in colon cancers. Oncology 61: 226-233

White DE, Cardiff RD, Dedhar S, Muller WJ (2001) Mammary epithelialspecific expression of the integrin-linked kinase (ILK) results in the

induction of mammary gland hyperplasias and tumors in transgenic mice. Oncogene 20: $7064-7072$

Yip-Schneider MT, Lin A, Barnard D, Sweeney CJ, Marshall MS (1999) Lack of elevated MAP kinase (Erk) activity in pancreatic carcinomas despite oncogenic K-ras expression. Int J Oncol 15: 271-279 